\title{
Author Correction: Ketamine can reduce harmful drinking by pharmacologically rewriting drinking memories
}

\author{
Ravi K. Das (D), Grace Gale, Katie Walsh, Vanessa E. Hennessy, Georges Iskandar (D, Luke A. Mordecai, \\ Brigitta Brandner, Merel Kindt, H. Valerie Curran \& Sunjeev K. Kamboj
}

Correction to: Nature Communications https://doi.org/10.1038/s41467-019-13162-w, published online 26 November 2019.

The original version of this article contained several errors as described below.

The significance bar for ' $p<0.004$ ' was incorrectly placed above the RET + PBO group in Fig. $2 \mathrm{~b}$. The correct version places it above the 'No RET + KET' group. Figure 3 contained an error, the data points shown in the middle and lower panel had been inadvertently duplicated during the revision process. This has been corrected. The 'Author contributions' incorrectly read 'S.K.K. managed the research and edited the paper'. The correct version states 'S.K.K. managed the research and edited the paper, helped design the study and secured funding'. The description of dose of ketamine used in the 'Methods' incorrectly read ' $350 \mathrm{ng} / \mathrm{dl}$ '. The correct version states ' $350 \mathrm{ng} / \mathrm{ml}$ ' in place of ' $350 \mathrm{ng} / \mathrm{dl}$ '. These errors have been corrected in both the PDF and HTML versions of the article.

The original version of this article contained two errors in the Supplementary Information.

The description of the units of ketamine used in Supplementary information on page 3 and page 4 incorrectly read 'ng/dl'. The correct version states ' $\mathrm{ng} / \mathrm{ml}$ ' in place of ' $\mathrm{ng} / \mathrm{dl}$ '. A sentence on page 6 incorrectly read 'This reflected significant acute increases in hedonic tone from pre-drug to on-drug in the groups receiving ketamine'. The correct version states 'decreases' instead of 'increases'. The HTML has been updated to include a corrected version of the Supplementary Information.

Published online: 11 June 2020

Open Access This article is licensed under a Creative Commons Attribution 4.0 International License, which permits use, sharing, adaptation, distribution and reproduction in any medium or format, as long as you give appropriate credit to the original author(s) and the source, provide a link to the Creative Commons license, and indicate if changes were made. The images or other third party material in this article are included in the article's Creative Commons license, unless indicated otherwise in a credit line to the material. If material is not included in the article's Creative Commons license and your intended use is not permitted by statutory regulation or exceeds the permitted use, you will need to obtain permission directly from the copyright holder. To view a copy of this license, visit http://creativecommons.org/licenses/by/4.0/.
}

(c) The Author(s) 2020 